\title{
Intensification of punishment effects through exposure to prolonged, fixed-duration shocks: The role of shock cues as a stimulus for fear
}

\author{
D. CHRIS ANDERSON, CHARLES R. CROWELL, MICHAEL DEPAUL, and JOHN MCEACHIN \\ University of Notre Dame, Notre Dame, Indiana
}

\begin{abstract}
Three experiments tested the hypotheses that (1) the onsets of prolonged, fixed-duration treatment shocks (shock treatment, or ST) serve as cues for fear conditioning to the ongoing painful effects of these stimuli, and (2) this acquired fear transfers to and influences shock-motivated test performances in predictable ways. Experiments 1 and 2 involved spaced post-ST presentations of very brief shocks (a presumed analogue of the onsets of treatment shocks) as a means of extinguishing the fear putatively associated with shock cues. This procedure reduced defecation by ST subjects over blocks of extinction sessions and nullified the punishment intensification effect that was otherwise shown to be a consequence of ST. As a further test of the shock-cue hypothesis, Experiment 3 involved relatively massed presentations of these brief shocks prior to ST in a latent-inhibition procedure (Lubow, 1973). This briefshock regimen also nullified the ST punishment intensification effect but did not impair the transituational transfer of contextual fear. In contrast, the group that was given the same brief shock regimen following ST showed enhancement of the punishment effect. With respect to current theoretical accounts of ST effects, these data were most consistent with notions that rely on an acquired-fear construct.
\end{abstract}

Exposure to a series of prolonged and intense fixedduration (i.e., inescapable) shocks has been shown both to depress nonaversively motivated behaviors (Anderson, Crowell, Koehn, \& Lupo, 1976; Minor, 1990) and to influence physiochemical outputs (Anisman \& Sklar, 1979; Levine, Madden, Connor, Moskal, \& Anderson, 1973; Maier et al., 1980; Weiss et al., 1981) in a variety of later test situations. However, the most widely studied test outcome of this treatment has been the impairment of escape and/or avoidance behavior (Crowell \& Anderson, 1981; Maier, Albin, \& Testa, 1973; Overmier \& Seligman, 1967).

A prominent explanation of the many deleterious effects of exposure to prior inescapable shocks (shock treatment, or ST) has been called the "learned helplessness hypothesis." According to this account, the physical properties of shock are less important than the responseoutcome contingency characterizing the way that this treatment is given (Maier, Seligman, \& Solomon, 1969). Since the various features of fixed-duration shocks seem to occur independently of any responses that might be emitted, organisms are believed to learn that their behavior is unrelated to shock parameters, as well as possibly to lose motivation to react. This account has thus seemed to explain why organisms often appeared unresponsive in later test situations and why they sometimes seemed retarded in learning new response-outcome associations (Maier \& Seligman, 1976).

Portions of this research were presented at the 1991 meeting of the Psychonomic Society, San Francisco. Requests for reprints should be sent to D. C. Anderson, 590 Ridgewood Rd., Tillamook, OR 97141.
Brookshire, Littman, and Stewart (1961) proposed a quite different earlier account for the proactive effects of ST in asserting that prolonged exposure to fixed-duration shocks could result in the conditioning of skeletal postures to the cues of the ST environment. They argued further that emotional responses (i.e., fear) could become conditioned to the stimuli associated with shock delivery. Either of these response tendencies could influence subsequent performance if they generalized to the test environment as a result of common transsituational cues.

This theory (Brookshire et al., 1961) was the source of considerable early interest in the role of conditioned fear as an explanatory account for the proactive effects of ST (e.g., Anderson, 1966; Anderson, Cole, \& McVaugh, 1968; Kurtz \& Walters, 1962; Pearl, Walters, \& Anderson, 1964). But the provocative findings of Seligman and Maier (1967) and Overmier and Seligman (1967) abruptly shifted the nature of research in this area toward the neocognitive learning theory emerging from the work of Solomon and his students (e.g., Maier et al., 1969; Rescorla, 1967). Accordingly, the dominant account of the effects of exposure to inescapable shock for the next 20 years was the "learned helplessness" hypothesis.

Alternative conceptions nonetheless were advanced during this period. For example, the conditioned skeletal response mechanism proposed by Brookshire et al. (1961) resurfaced under the guise of "interacting-response theory" (Anderson, Crowell, Cunningham, \& Lupo, 1979; Balliene \& Job, 1991; Crowell \& Anderson, 1979; Glazer $\&$ Weiss, 1976). Various neurochemical depletion accounts of the proactive effects of exposure to inescapable shock were also proposed (Anisman, DeCatanzaro, \& Remington, 1978; Weiss, Glazer, \& Pohorecky, 1976). In- 
deed, in recent theories, researchers have focused on the importance of the noncognitive byproducts of ST, maintaining that exposure to inescapable shock should be considered as a "baseline" stress condition (Minor, Dess, \& Overmier, 1991; Overmier, 1988). From this viewpoint, many possible extrinsic conditions, like a shock escape contingency, may "modulate" the behavioral and/or biophysiological consequences of this stressor (Overmier, 1988).

There has also been a resurgence of interest in the role of conditioned fear in explaining proactive effects of ST (Maier, 1990; Mineka, Cook, \& Miller, 1984; Minor, 1990). This interest stems from findings suggesting that inescapable shock, when compared with escapable shock or no shock, may promote the conditioning of unusually high levels of fear in response to the ambient cues of the treatment environment. In this case, the generalization mechanism proposed by Brookshire et al. (1961) might operate to produce greater levels of fear in a subsequent test environment for inescapably shocked rats than for those subjected to escapable shock. This differential fear could result in greater levels of freezing and more interference with an active test response for inescapably shocked rats.

Conditioned fear to the contextual cues resulting from fixed-duration shocks that generalizes to various test situations has also been used as a possible explanation of the punishment-augmentation effects that have been reported following ST (Anderson, 1993; Anderson et al., 1968; Hollis \& Overmier, 1973; Walters \& Rogers, 1963). With a passive learning test situation such as the punishment paradigm, generalized fear from the ST environment would be expected to augment or intensify, rather than offset, punishment-induced response suppression.

This interpretation has been challenged, however, by attempts to extinguish contextually mediated fear in ST subjects prior to testing (Anderson, 1966; Anderson et al., 1968; Kurtz \& Pearl, 1960; Pearl et al., 1964). Such extinction would be expected to reduce or eliminate punishment intensification to the extent that it is dependent on generalized fear. Although these studies show that extinction-like procedures results in marked attenuation of prepunishment manifestations of contextually mediated fear in the test environment, no significant diminution of punishment intensification was observed for inescapably shocked subjects.

At least two conclusions could be drawn from the apparent failure of these extinction-like procedures following ST to reduce or eliminate punishment intensification effects. One is that factors other than contextual fear may be responsible for punishment intensification and other deleterious consequences of exposure to inescapable shock (see Anderson et al., 1979; Black, 1977; Brookshire et al., 1961; Levis, 1976; Maier \& Seligman, 1976). Alternatively, it is possible that the extinction-like procedures of Anderson (1966), Anderson et al. (1968), Kurtz and Pearl (1960), and Pearl et al. (1964) did not completely extinguish fear to all of the cues that were common to both treatment and test settings. For example, one stimulus often common to ST and testing environments is the shock itself. The relevance of shock as a source of important contextual cues has been largely overlooked throughout most of the work in this area.

\section{EXPERIMENT 1}

Several lines of evidence support the possibility that under some conditions, shock cues may become fear arousing. First, as compared with the shocks employed in standard fear conditioning studies, those used in studies of proactive shock treatment effects are of unusually long durations. This allows for the stimulus properties of shock onset to be "paired" with continued and painful exposure to the same event, thereby perhaps endowing these cues with conditioned aversive properties. In essence, subjects may learn that the cues of shock onset "predict" a prolonged exposure to the painful event. In turn, this could enhance the total aversiveness of the inescapable shock regimen. Findings of attenuated basal skin resistance and of elevated defecation and corticosterone levels in ST subjects (Anderson, Crowell, Boyd, \& Hantula, 1995; Anderson et al., 1976; Levine et al., 1973) are consistent with this possibility. Crowell (1974) provided even more direct evidence that shock cues can serve a CS-like function. He showed that a weak shock previously paired with stronger shocks promoted faster escape learning and greater suppression of appetitive responding than did a weak shock that was not thus paired for appropriate controls.

This analysis implies that the duration of treatment shocks may be a critical factor in producing conditioned aversion to shock cues in that longer shocks may result in more salient "pairings" of shock onset with the cues that follow from continued shock exposure. Also, a longer shock may serve as a more functionally intense "US" to reinforce any fear associated with shock onset. In this view, longer duration inescapable shocks should come to have a greater degree of total aversiveness, and thereby should have more deleterious effects on subsequent test performances than should shorter duration shocks. Support for this possibility is supplied in the reports of Crowell and Anderson (1981) and Overmier and Seligman (1967, Experiment 2). Support may also be found in Bersh, Whitehouse, Laurence, Blustein, and Alloy (1990), who found that a signal associated with the duration of uncontrollable shock enhanced impairment of subsequent escape responding.

The purpose of Experiment 1 was to explicitly evaluate the possibility that cues associated with the onset of prolonged, inescapable treatment shocks can serve as CSs for the acquisition of fear that, in turn, contributes to an intensified response to punishment in subsequent testing. To assess this possibility, an extended series of highly spaced brief shocks was introduced for some groups following inescapable shock but prior to punishment testing. This brief shock regimen was designed to simulate onset of the inescapable treatment shock and thereby to "extinguish," or at least reduce, any conditioned aversive aspects of shock cues. The presumed effectiveness 
of this brief-shock "extinction" procedure was guided by several assumptions.

First, it was assumed that a brief shock of the same type and intensity as those of the longer inescapable treatment shock would supply many of the same cues, especially those associated with shock onset. It was also assumed that because of their extremely short duration and wide spacing, these brief shocks would have mainly CS-like, not US-like, properties. It was thus reasoned that repeated, posttreatment exposures to these brief shocks would be analogous to multiple nonreinforced presentations of critical CS aspects of the longer inescapable shocks. If so, this should result in extinction of fear previously conditioned to the cues of shock onset that, in turn, could ameliorate punishment intensification in subsequent testing.

Converging evidence regarding the presumed role of acquired fear in this study required an index of emotion that was unrelated to the behavior promoted by the test task. Defecation was used as such an index, since, as noted above, this measure is strongly correlated with various indices believed to reflect ST-induced fear. Thus, defecation rate during the interpolated brief-shock procedure served as an index of fear extinction.

\section{Method}

\section{Subjects}

Twenty naive albino 90- to 100-day-old Sprague-Dawley rats were purchased from Harlan Sprague-Dawley, Inc. All were gentled, weighed, and acclimated to the laboratory for 6 days and were then placed on a 23-h, 50-min water-deprivation regimen until each achieved $80 \%$ of its 6th-day, ad-lib body weight (maintained thereafter throughout the study). All features of this experiment (including shock parameters, animal-care practices, restraint and deprivation procedures, etc.) conformed with those approved by the campus Animal Research Screening Committee (ARSC) subsequent to the conduct of this research (protocols available on request).

\section{Treatment and Extinction Apparatus}

Tight-fitting cylindrical chambers composed of circular brass rods, described by Anderson, Plant, and Paden (1967), served as the ST and extinction environment. Overall, the chambers were $4.94 \mathrm{~cm}$ in diameter and $17.1 \mathrm{~cm}$ long. The brass rods were $.31 \mathrm{~cm}$ long, molded into circles, and mounted flush to the inside surfaces of three $.62-\mathrm{cm}$-wide plastic railings that abutted to solid plastic endplates. Rats were inserted into these chambers through a hinged circular door cut into one of the endplates. Each chamber was housed separately in a sound-deadened, ventilated, and unlighted environment. Both the treatment and test shocks (delivered through a Gerbrands shock scrambler) were supplied by a dc constant-current tuberegulated shock source (Campbell \& Teghtsoonian, 1958). Treatment and test stimulus presentations were controlled by programming modules and a minicomputer (which also collected the test data) located in a distant room. Treatment, extinction, and test shock intensities were set at $0.8 \mathrm{~mA}$.

\section{Test Apparatus}

A $21 \times 23 \times 20 \mathrm{~cm}$ Gerbrands operant chamber (Model C), housed in a sound- and light-controlled and ventilated refrigerator shell, was used for testing. The floor was composed of eighteen $0.296-\mathrm{cm}$-diameter grid bars spaced $1.0 \mathrm{~cm}$ apart (centers). These bars and the two aluminum end walls (Plexiglas sides) were connected to the switched, scrambled output of the shock source. A bent stainless steel drinking tube was mounted in a rubber collar in- serted through one of the aluminum ends of the chamber (described in Cunningham \& Anderson, 1974) and was connected to one electrode of a Lehigh Valley drinkometer (Model 1520). A plastic partition was placed near this end wall in order to shield all but the rat's mouth and tongue from the tip of the drinking tube. The grid floor of the chamber served as the other electrode, and the drinkometer was briefly switched out of the circuit when test shock was given.

\section{Design}

ST was given to one of two groups of 10 rats each. All subjects were thereafter returned to the treatment chamber 60 times, and half of each group was given a brief shock during some of these sessions, thereby yielding four groups in all. The controlling paradigm was a $2(\mathrm{ST}$, no ST) $\times 2$ (brief shocks, no shocks) $\times 2$ (test trials) multivariate analysis of variance (MANOVA) design involving two between-groups variables and one within-subjects variable. Henceforth, the groups will be designated as follows: Group NST, no shock treatment, and no brief shocks; Group ST, shock treatment only; Group NST-S, no shock treatment, but brief shocks; Group ST-S, both shock treatment and brief shocks.

\section{Procedure}

Following 10 days at $80 \%$ body weight, all rats were given five daily 10-min water-licking sessions in the operant chamber (Days $1-5$ ), and the number of licks was recorded. The number of licks on Day 5 was used to rank order subjects and form four groups according to a randomized-blocks procedure. Daily watering occurred thereafter in home cages. Either 2 or 3 of the rats of each group were given their treatment in the a.m. and weighed and given water $12 \mathrm{~h}$ later. The remaining subjects of each group received this sequence on a reverse time schedule. The ST involved placement of individual rats into the treatment coil for 10 min on each of Days 6-10. Rats of two of the groups were exposed without warning to a fixedduration (3-min) scrambled shock beginning 2-5 min (randomly determined) following placement into the coil on each of these days. Subjects of the remaining two groups were also given 10 -min placements into the coil but were not shocked. The chamber was wiped clean with a damp cloth between subjects in order to minimize carry-over odor contamination (see Minor \& LoLordo, 1984).

Individual placements into this chamber continued for an additional 15 days (Days 11-25), but at 6-h instead of 24-h intervals (i.e., four 10-min sessions per day per subject), for a total of 60 post-ST placements in all. Forty of these 60 sessions were chosen randomly for the administration of a single $0.25-\mathrm{sec} 0.8-\mathrm{mA}$ shock to the rats of one ST and one no-ST group. This was accomplished by programming the lab computer to, beginning 10 -sec after insertion of the subject into the chamber, divide each session into 590 one-second time frames and administer a single shock during one of these randomly chosen seconds. Emission of fecal material was individually determined for each of the extinction sessions by placement of a fresh, white paper towel beneath the coil for each rat. Thereafter, independent observations for the presence of fecal deposits were made by two experimenters ( $100 \%$ agreement ratios) at the end of each session.

Each rat was reintroduced into the operant test chamber for 10 min sessions on each of Days 26-28 to re-stabilize baseline lick rates. On Day 29 , two test trials were given, in which, immediately following the 100th lick, a 0.5 -sec $0.8-\mathrm{mA}$ scrambled shock was delivered through the grid floor to each rat. Latencies to the first 100 licks prior to, and to the 10th lick following, this shock were recorded. The same procedure was repeated for a second test trial. That is, a second shock was given immediately upon completion of 110 licks following the initial shock. Latencies to make the 100 licks preceding this second shock, and then to make 10 and then the next 100 licks thereafter also were recorded. If a rat failed to make either the first (within $3 \mathrm{~min}$ following the initial shock) or the second set of 10 and 100 licks (following the second shock), it was removed from the cage and assigned the maximum score. 


\section{Results}

\section{Post-ST Data: Defecation Scores}

The percent of each consecutive set of 10 extinction sessions in which defecation occurred was determined for each subject. These scores were averaged for each group and are displayed in the left portion of Figure 1 as a function of blocks of 10 sessions. Of the two groups given the brief shock regimen, the percentage of sessions in which defecation occurred was higher for subjects that also had been shock treated (Group ST-S). These groups showed either no reduction (Group NST-S) or only a modest (arithmetic) decline in rate over the six blocks (Group ST-S). The ST-only group (Group ST) also showed a high rate of defecation similar to Group ST-S on the two initial blocks, but declined steadily thereafter on this measure over the remaining session sets to a level (Block 6) that approximated the near-zero rate of the nonshocked control group (Group NST).

These observations were supported statistically by subjecting the data to a 2 (ST, no ST) $\times 2$ (brief shock, no shock) $\times 6$ (blocks) multivariate analysis of variance (MANOVA; O'Brien \& Kaiser, 1985; blocks were a within-subjects variable). Significant outcomes were obtained for the effects of ST $[F(1,16)=28.47]$, extinction shock $[F(1,16)=11.53]$, and blocks $[R(5,12)=8.12]$, and for the ST $\times$ blocks $[R(5,12)=6.4]$, and brief shock $\times$ blocks $[R(5,12)=2.98]$ interactions. The $R$ value for the three-way ST $\times$ brief shock $\times$ blocks interaction $[R(5,12)=3.1]$ did not quite achieve significance.

Two follow-up analyses were performed to evaluate these interactions. One entailed a $2(\mathrm{ST}$, no ST) $\times 6$ (blocks) analysis to compare defecation rates for the two groups given brief shocks (i.e., Groups ST-S and NST-S). The effect for ST $[F(1,8)=8.3]$ was statistically reliable, but neither the effect for blocks $[R(5,4)=3.5]$ nor the treatment $\times$ blocks interaction was $(p s>.07)$. The hypothesis that the brief shock regimen should promote fear extinction for ST subjects suggested that a decline over blocks in defecation rate should have occurred for Group ST-S. Blocks-within-groups tests were accordingly performed for each of the two brief shock conditions. The $F$ value for Group ST-S (but not for Group NST-S) approached but did not achieve statistical reliability $[F(5,20)=2.31, p=.083]$.

The second follow-up analysis involved the two groups not given extinction shocks: Groups ST and NST. Reliable $F$ values were obtained for all three effects $\left[F_{\mathrm{ST}}(5,40)=\right.$ $\left.11.17, R_{\text {blocks }}(5,4)=21.05, R_{\mathrm{ST} \times \text { blocks }}(5,4)=23.3\right]$. Follow-up, blocks-within-groups analyses produced a reliable $F$ value for Group ST $[F(5,20)=10.1]$, but not for the nonshocked (NST) control group $[F(5,20)=$ 3.03]. Although defecation rates differed for these groups on Block 1, they were statistically identical by Block 6 $(F<1.0)$.

\section{Testing}

Pretest licking. Although the groups were equated for lick rates prior to the treatment and extinction sessions $(p>.30)$, they nonetheless differed from one another in mean seconds to achieve 100 licks prior to the initial test shock on Day 29 of the experiment. These data are displayed by group in the left portion of Figure 2 . Surpris-

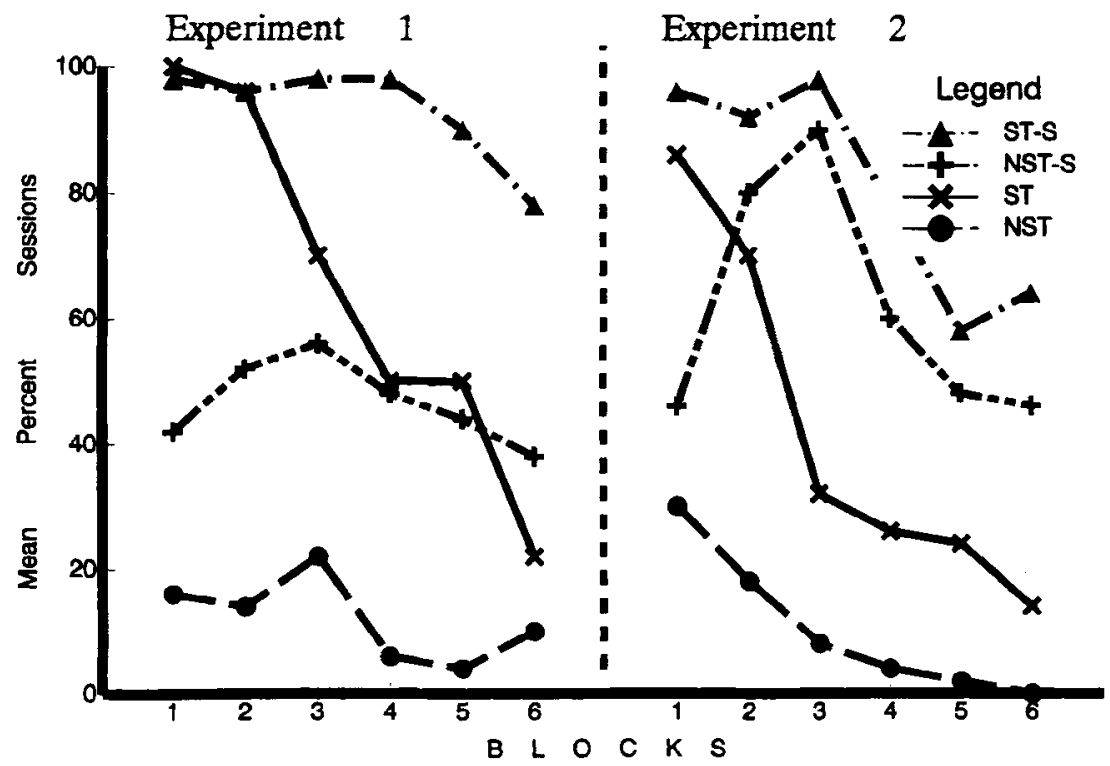

Figure 1. Mean defecation rate, calculated as a percentage of blocks of 10 sessions for each subject, and averaged for each group. Group NST did not receive shock treatment (ST) or brief shocks; Group ST received ST only; Group NST-S was given brief shocks but not ST; Group ST-S was given both ST and brief shocks. The left portion is a display of group averages for Experiment 1 (average inter-brief-shock interval $=6 \mathrm{~h}$ ); the right portion, of averages for Experiment 2 (average interval $=12 \mathrm{~h}$ ). 
ingly, the non-ST groups averaged somewhat longer times than did the two that received ST $[F(1,16)=5.25]$. And, although no other significant effects emerged from an analysis of these data, follow-up a posteriori (NewmanKeuls) contrasts yielded reliable differences for all comparisons involving Group ST-S.

Punishment training. Time taken for each rat to make the first 100 licks on Day 29 (i.e., pretest scores) was used as a covariate in a 2 (ST, no ST) $\times 2$ (brief shock, no shock) $\times 2$ (trials) analysis of covariance (ANCOVA) of the times to make 10 licks following each of the two test shocks. Both the original (clear columns) and the adjusted (after correction by the ANCOVA) group means (solid columns), averaged over the two test trials, are shown in the right portion of Figure 2 . The adjusted means reveal an ordered pattern in which Group ST showed the longest, Groups ST-S and NST-S intermediate, and Group NST the arithmetically shortest mean times to achieve the 10th response following test shock. Only modest arithmetic deviations from this pattern are evident in the unadjusted data, the most conspicuous one perhaps being that Group ST-S exhibited the shortest mean time of all subject sets.

The ANCOVA yielded significant $F$ values for the effects of ST $[F(1,15)=5.9]$ and trials $[F(1,15)=35.47]$, but not for any others. However, since it was hypothesized that Group ST would be the only one to show a punishment enhancement effect, appropriate a priori contrasts were performed. These resulted in significant differences between Group ST and each of the other three [all $t \mathrm{~s}(15)>2.1$ ], whereas the other three groups did not differ among themselves.

\section{Discussion}

Given that defecation rate indexed fear, the elevated fecal output for initial extinction session blocks provided evidence of greater fear to contextual stimuli for Group ST over NST subjects. Moreover, the elevated defecation rate of Group ST-S over that of both Groups NST-S and ST for all extinction sessions coincides with the view that shock cues also were a source of acquired fear for ST subjects. In addition, the near-zero defecation rate achieved by the final set of extinction sessions for Group ST confirmed other findings that repeated post-ST introductions into the treatment chamber is an effective way of extinguishing contextual fear. And, given that waterlicking rates are sensitive to fear transferred from the ST chamber (Cunningham \& Anderson, 1974), the finding that baseline lick rates for both ST groups in this study were either the same as, or faster than, that of Group NST confirmed the absence of contextual fear for all subjects in the test environment.

As was expected, Group ST, relative to Group NST, showed a marked punishment intensification effect. This is to be contrasted with the relatively attenuated effect of punishment for the ST group that was given the briefshock extinction procedure (Group ST-S). This finding is consistent with the present rationale that the briefshock procedure extinguished fear of ST cues, thus pre-

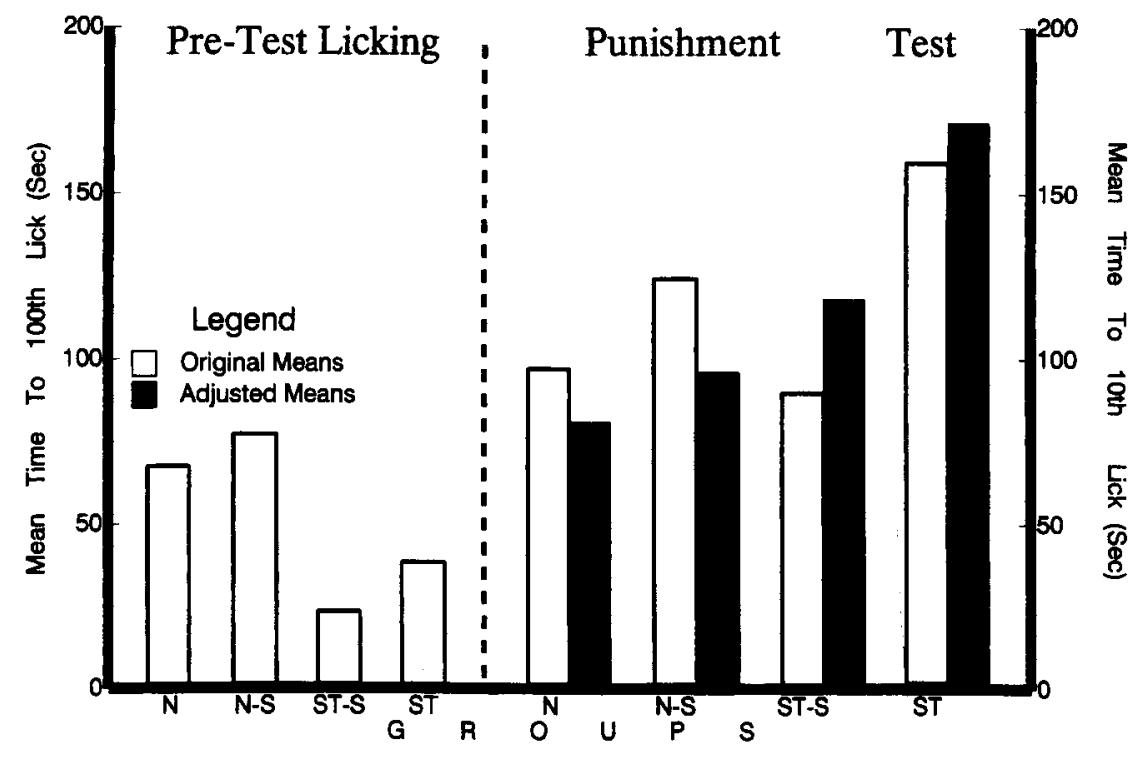

Figure 2. Mean time (by group) to make 100 lick responses prior to the first test shock (left portion) and to make 10 responses following each of two response-contingent test shocks (open columns). The second test shock was made contingent on the 110th response following the initial test stimulus. Dark columns are means based on adjustments resulting from an ANCOVA applied to the same data. Group N was not given ST or brief shocks; Group N-S was given brief shocks, but no ST; designations for Groups ST-S and ST are the same as for Figure 1. 
sumably removing a source of response compatibility with that engendered by the punishment test. However, this test performance of Group ST-S (and its NST counterpart, Group NST-S) was arithmetically intermediate between the performance of Groups ST and NST. This outcome may be consistent with the failure by Group ST-S to show a marked decline in defecation rate over extinction sessions, thereby raising the possibility that the brief shock procedure may not have been fully effective in extinguishing the fear putatively associated with shock cues. Presumably, had the fear associated with shock cues been more completely extinguished for Group ST-S, then more complete nullification of the ST punishment intensification effect would also have occurred for these subjects.

\section{EXPERIMENT 2}

As noted, a factor believed important in promoting fear extinction to shock cues is the degree of temporal spacing between the brief shocks. The leading assumption here is that the shock cues, in serving a CS-like function, could be presented in such a way as not to have a US-like effect as well. Indeed, the choice of the abbreviated 0.25 sec duration was also guided, in part, by an attempt to bypass any US-like function that might otherwise have been associated with exposure to these truncated stimuli. That is, a stimulus duration was chosen that would be registered as shock but that presumably would not produce all of the painful biobehavioral consequences otherwise associated with ST. Pilot work revealed that durations shorter than $0.25 \mathrm{sec}$ did not appear to be so registered, and that longer durations (e.g., the 0.5 -sec test shock of Experiment 1) countered the extinction of fear to shock cues.

Nonetheless, the possibility remained that the brief shock procedure mimicked the US-like properties of ST, since this method was not fully effective in promoting a decline in defecation rate or in fully mitigating the effects of ST on punishment training. However, since Group ST-S showed some reduction in defecation rate over blocks in Experiment 1, we reasoned that an even longer interval separating each brief shock might (as opposed to using even shorter durations) remedy this circumstance. This might permit more complete extinction of any fear that might have been conditioned to shock cues. In Experiment 2, we evaluated this possibility by doubling the average interval between brief shock exposures that was used in Experiment 1. The expectations for Group ST-S, based on use of this longer interval, were (1) a reliable decline over session blocks in defecation rate to a (2) terminal level approximating that of Group NST-S, and (3) more complete remission of punishment intensification.

To more fully evaluate the respective contributions of contextual and shock-cue-mediated sources of fear, a third ST group was included in this experiment that received no extinction treatment of any sort. In Experi- ment 1 , all subjects were handled and placed into the experimental chamber during the extinction phase even though only two groups were exposed to the brief-shock procedure. This (partly) might have extinguished contextrelated fear for all subjects. However, for this additional group, both sources of conditioned fear should remain intact. Thus, an ST group with no handling or chamber exposure following ST and before testing should transfer to the test environment both contextually based fear and fear mediated by shock cues. The result should be a relatively marked suppression of pretest licking (Cunningham \& Anderson, 1974) and an especially pronounced punishment enhancement effect in response to test shock.

\section{Method}

\begin{abstract}
Subjects
Twenty-five male naive albino 90- to 100-day-old Sprague-Dawley rats were used. Acclimation to the laboratory, handling, and the waterdeprivation regimen were as in Experiment 1. All aspects of the experiment similarly conformed with ARSC protocols.
\end{abstract}

\section{Apparatus}

The chambers and associated equipment were those from Experiment 1 .

\section{Design}

The design was as that outlined for Experiment 1, except that an additional fifth group was given ST but was not returned to the treatment chamber thereafter or handled at all until testing.

\section{Procedure}

With two exceptions, pretreatment lick training, the group-equating procedure, ST, extinction shock, and test procedures were the same as in Experiment 1. One exception was that, as noted, the subjects of three instead of two groups were individually given the ST regimen of five 3-min unsignaled shocks administered at the rate of one/day (Days 6-10). The second exception was that the brief shock procedure for two ST and two non-ST groups entailed 10-min placements into the ST chamber at $12-\mathrm{h}$ (rather than 6-h) intervals for a total of 60 sessions. These sessions thus occurred over Days 11-40. Again, the subjects of one ST and one non-ST group were administered single 0.25 -sec, 0.8 -mA shocks in 40 randomly selected sessions (as in Experiment 1). Subjects of the third ST group (Group ST$\mathrm{NH})$ were not handled on Days 11-40. In order to maintain $80 \%$ body weights for these subjects, the access periods to water were determined by the respective average daily durations required to maintain the weights of the handled rats. Defecation measures for all groups (except Group ST-NH) were collected in the same way as in Experiment 1 . Three days of pretest licking (Days $41-43$ ) and the two punishment test trials (Day 44) were administered in the same way as in Experiment 1.

\section{Results \\ Post-ST Data: Defecation Scores}

The data are again expressed as mean percentage of sessions (blocks of 10 ) in which defecation occurred for each group, and are shown in the right panel of Figure 1. Although the pattern of these data is similar to that for Experiment 1, certain differences are apparent. For example, while the defecation rate for the brief-shock group (Group NST-S) was again intermediate to that for Groups 
ST-S and NST, it was higher overall and showed a somewhat more distinctive, inverted U-shaped pattern than did its counterpart in the first study. Further, whereas the very high defecation rate for Group ST-S was about the same as in Experiment 1 for the first 3 blocks, it then showed a marked decline to a terminal level that was about the same as for Group NST-S for the final 2 sessions. Finally, although the pattern of rates for the groups that were not given brief shocks in extinction also was similar for both experiments, the rate of decline over blocks was somewhat more precipitous for Group ST, and the terminal levels were lower for both groups in the present experiment.

A 2 (ST, no ST) $\times 2$ (brief shocks, no shocks) $\times 6$ (blocks) MANOVA applied to these data revealed significant outcomes for the effects of ST $[F(1,16)=14.4]$, extinction shocks $[F(1,16)=41.6]$, and blocks $[R(5,12)=$ 12.2], and for the ST $\times$ blocks $[R(5,12)=4.1]$ and briefshock $\times$ blocks $[R(5,12)=6.97]$ interactions. Followup MANOVAs to determine the nature of the brief-shock $X$ blocks interaction revealed a significant blocks effect both for groups that received brief shocks $[R(5,4)=12.22]$ and for those that did not $[R(5,4)=7.1]$. However, the defecation rate function for Group NST-S was apparently nonmonotonic, as was indicated by a significant initial increase in defecation for this group over Blocks $1-3[R(2,7)=8.6]$.

Follow-up MANOVAs applied separately to ST and NST groups revealed that the ST $\times$ blocks interaction was due to reliable ST effects on early blocks but not on the final session block [e.g., $F(1,8)=2.58, p=.15$, for Block 6].

\section{Testing}

Pretest licking. Mean total licks were the same for the five groups on Day 5 prior to ST $(F<1.0)$. Further, excluding Group ST-NH, mean times to the 100th lick prior to the first test shock (Day 44), shown on the left side of Figure 3, were relatively short and statistically identical. All $F$ values not involving Group ST-NH were less than unity. In contrast, planned comparisons involving Group ST-NH and each of the others resulted in significant outcomes (all $p$ s $<.01$ ).

Punishment training. These data were analyzed with the same ANCOVA and MANOVA models as in Experiment 1 . The covariate again was time to make the first 100 licks prior to the initial test shock. Both the original and the adjusted mean times to achieve the 10th lick following shock, averaged for each group over the two test trials, are shown on the right side of Figure 3. As with Experiment 1, comments based on the adjusted scores apply equally to both sets of means.

All groups showed increases over their respective baseline performances in mean lick times following test shocks. However, the magnitude of these increases varied as a function of treatment and/or extinction conditions. The most pronounced increases in mean lick times were for the two ST groups that did not receive brief shocks, the largest of these being that for the nonhandled subjects (Group ST-NH). In contrast, the remaining groups showed relatively shorter and similar times, with the extinctionshock-only group (Group NST-S) being the arithmetically fastest of all.

The 2 (ST, no ST) $\times 2$ (brief shock, no shock) $\times 2$ (trials) ANCOVA (exempting Group $\mathrm{ST}-\mathrm{NH}$ ) yielded

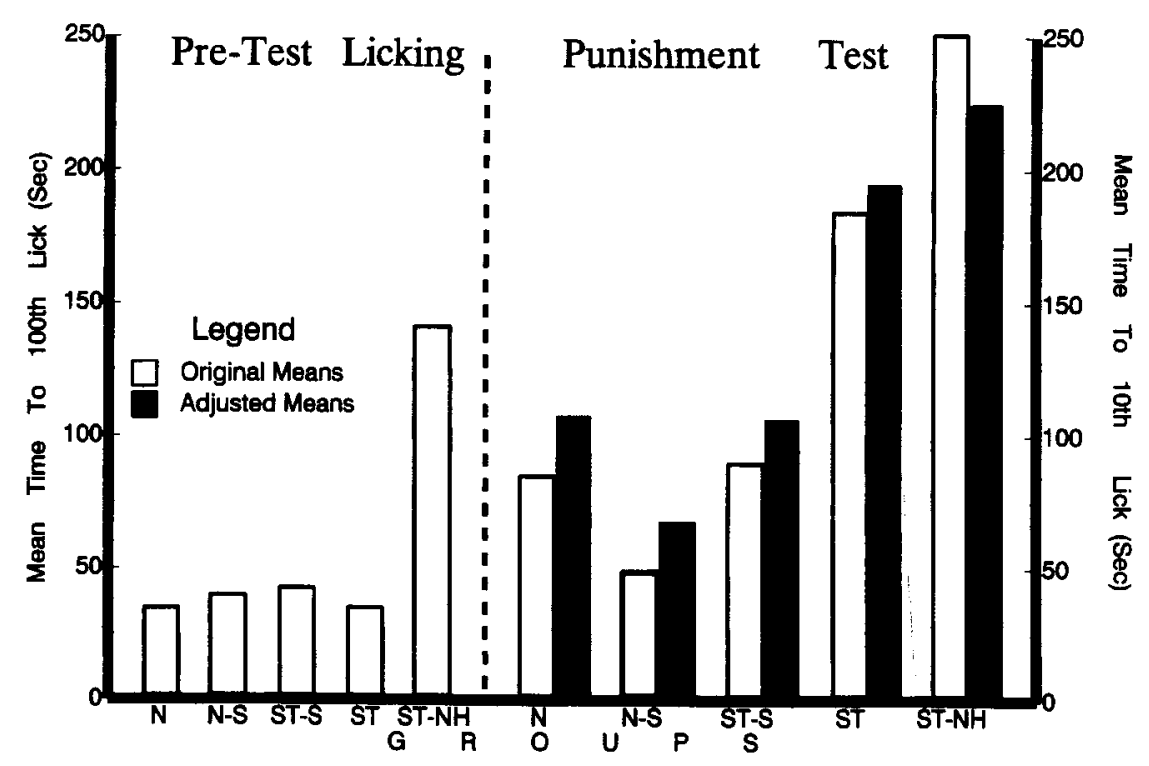

Figure 3. Mean lick times derived from punished test performances for the groups of Experiment 2 . The data were collected in the same manner and the legends are as outlined for Figure 2. In addition, test data are displayed for a fifth group that was given ST, no brief shocks, and otherwise was not handled prior to testing (i.e., Group ST-NH). 
significant statistical outcomes for the effects of ST $[F(1,15)=13.45]$, brief shocks $[F(1,15)=17.03]$, and trials $[F(1,15)=14.5]$. The $F$ values for the interactions between ST and trials $[F(1,16)=3.1]$, brief shocks and trials $[F(1,16)=4.0]$, and ST $\times$ brief shocks $\times$ trials $[F(1,16)=4.0]$ approached or achieved normally accepted levels of statistical significance. Planned comparisons justified by theoretical expectations (and the outcomes of Experiment 1) were performed between ST and no-ST groups. All contrasts involving Group ST achieved statistical significance (all $p s<.04$ ), but none involving the three remaining groups were significant (all $p s>.20$ ).

Of the several possible comparisons of times to the 10th lick following each of the two test shocks involving Groups ST and ST-NH, those that also included Group ST-S appeared to be the most pertinent. This is because, in performing like the two NST control groups, Group ST-S provided an appropriate baseline for evaluating respective contributions to test performance of the various sources of fear believed to result from ST per se. As shown in Figure 3, overall lick latencies for Groups ST and ST-NH were markedly longer than for Group ST-S. What is not revealed in Figure 3 is that, when not adjusted for baseline variations, the suppression of licking for the ST and ST-NH groups developed differently over the two test trials. While Group ST showed much less suppression (a shorter mean latency) on the initial than on the second test trial, Group ST-NH showed marked and equivalent suppression on both.

This outcome is most clearly revealed in the 3 (group: ST, ST $-\mathrm{S}, \mathrm{ST}-\mathrm{NH}) \times 2$ (trials) ANOVA applied to these data, in which all three $F$ values achieved statistical significance $\left[F_{\text {groups }}(2,12)=7.31 ; F_{\text {trials }}(1,12)=50.44\right.$; $F_{\text {groups }} \times$ trials $(2,12)=11.63$ ]. While the $F$ ratios for the groups effect for each trial were significant $\left[F_{\mathrm{s}}(2,12)=\right.$ 7.11 and 9.5 , respectively], the patterning of differences between groups across these trials changed. Groups ST $(M=87.7 \mathrm{sec})$ and $\mathrm{ST}-\mathrm{S}(M=66.9 \mathrm{sec})$ performed about the same following the initial punishment test shock $(p>$ .20 ), and both achieved the lick criterion significantly faster than did Group ST-NH $(M=219.8 \mathrm{sec} ; p s<.01)$. In contrast, whereas the mean latency to the 10 th lick was only modestly longer for Group ST-S $(M=109.12 \mathrm{sec})$ following the second punishment trial, most of the subjects in Groups ST $(M=277.8 \mathrm{sec})$ and ST-NH $(M=$ $279.3 \mathrm{sec}$ ) failed to achieve this lick criterion in the allotted 300 -sec period.

This pattern of differences changed when adjusted for baseline variations. The statistical outcome from the ANCOVA resulted in a near-significant $F$ value for groups $[F(2,11)=3.7]$ and in highly significant statistical outcomes for the effect of trials $[F(1,11)=46.23]$ and the groups $\times$ trials interaction $[F(2,11)=10.66]$. Follow-up analyses revealed that although Group ST-S provided the arithmetically fastest average time to the 10th lick on Trial 1 ( $M_{\mathrm{adj}}=101.5 \mathrm{sec}$; for Groups ST and ST-NH, $128.7 \mathrm{sec}$ and $144.2 \mathrm{sec}$, respectively) this performance was statistically indistinguishable from that of the other two groups $(F<1.0)$. An analysis of perfor- mances on Trial $2\left[F_{\text {groups }}(2,11)=7.3\right]$ revealed that while Group ST-S exhibited modestly longer times than those on Trial $1\left(M_{\text {adj }}=120.7 \mathrm{sec}\right)$, Groups ST $\left(M_{\text {acj }}=\right.$ $291.5 \mathrm{sec})$ and $\mathrm{ST}-\mathrm{NH}\left(M_{\mathrm{adj}}=254 \mathrm{sec}\right)$ again approached the $300-\mathrm{sec}$ cutoff criterion. This performance for Group ST-S was significantly different from that of the remaining two $(p s<.01)$, which did not differ from one another $(p>4)$.

\section{Discussion}

The present outcomes were generally consistent with those of Experiment 1. The ordinal relation in defecation rates between groups was the same and, except for Group ST-NH, prepunishment baseline lick times were quite short and essentially the same for these subject sets. The punishment contingency elevated mean lick times for all groups and, as in Experiment 1, this increase again was more pronounced for Group ST (and Group ST$\mathrm{NH}$ ) than for the remaining groups, which performed about the same. One noteworthy difference from Experiment 1 is that defecation rate decreased for all groups over the final four session blocks of the present experiment. Notwithstanding an inexplicable initial rise in defecation rate for Group NST-S, these decreasing functions were probably due to the longer interval between "extinction" sessions that was employed in the present experiment. This may have allowed for greater dissipation of carry-over residual emotionality resulting from the cumulative by-product of contextual fear and/or brief shock exposures in preceding sessions. The lower terminal defecation rates shown in the present experiment are also consistent with the possibility of greater overall fear extinction for all groups than occurred in Experiment 1. This could explain the two somewhat modest differences between the experiments in connection with the pretest baseline lick data.

Average baseline lick times were somewhat faster overall in Experiment 2 than in Experiment 1. Also, the handled groups in Experiment 2 did not differ among themselves in baseline lick rates. These outcomes are congruent with the expectation that the longer average time between brief shocks (as well as possibly the longer treatment-test interval) would be associated with more complete extinction of contextual fear in Experiment 2. Aspects of the present data are also consistent with the possibility of greater extinction of fear to shock cues for Group ST-S than was observed for this group in Experiment 1 . Not only did defecation rate decline to an overall lower level in the present experiment for this group, but the performance of these subjects when given test shock was statistically indistinguishable from that of the subjects in Group NST-S. Noteworthy, however, was that the terminal defecation rate for Group ST-S remained somewhat elevated arithmetically over that for this briefshock control group, thereby leaving open the possibility that shock cues remained modestly more aversive for these ST subjects. If so, the identical punishment functions of the ST-S and no-ST groups may have occurred 
because yet another factor was modified by the briefshock regimen (e.g., skeletal posturing?).

Experiment 2 also provided information relevant to the contributions of contextual and treatment-shock cues as separable sources of ST effects. If we consider first the pretest, baseline lick times, nonhandled ST subjects (Group ST-NH) showed a markedly longer average than the otherwise identical baseline performances of the two ST groups that were returned repeatedly to the ST chamber following treatment. Given equivalent pretreatment lick times for these three groups, the relatively greater suppression of baseline licking for Group ST-NH stands as an uncontaminated reflection of the contextually mediated fear that was acquired during ST and transferred to the test setting.

These outcomes may also reflect on an odor hypothesis of ST effects (Minor \& LoLordo, 1984; see also Maier, 1990). Although it could be argued that the baseline (and punishment test) variance characterizing Groups ST and ST-NH may have occurred partly because of the differential extinction of fear to odor cues associated with the treatment shocks, this reasoning would not apply to the same variance between Groups ST-NH and ST-S. Group ST-S rats continued to experience their own shock-related odors (i.e., defecation smells) during the extinction regimen, but neither displayed pretest suppression nor exhibited a punishment intensification effect in response to test shock.

The contribution of contextual fear to punished test performances may be inferred from a comparison of the mean lick times of Groups ST and ST-NH displayed in the right panel of Figure 3. The magnitude of the difference in the unadjusted means approximates (roughly) that shown between the baseline performances of these same groups. This suggests the possibility of an additive effect of contextual fear with the fear associated with shock cues. Note, however, that a modest difference in test performance remained after correction (with the ANCOVA statistical procedure) for this baseline variance. This is because Group ST performed about the same as did Group NST but differently than Group ST-NH on the first test trial. It was only on the second trial that these two ST groups performed the same and that both exhibited more suppression than did the no-ST controls. On the assumption that the Trial 2 suppression of Group ST is traceable to fear evoked mostly by the shock cues, the Trial 1 suppression of Group ST-NH can be viewed as a composite reaction based on both sources of fear.

\section{EXPERIMENT 3}

Although the data of Experiments 1 and 2 are consistent with the possibility that the brief shocks functioned as nonreinforced CS exposures to extinguish the fear associated with the cues of ST, this interpretation would be strengthened if it could be shown within the same paradigm that these stimuli exhibited yet other properties normally attributed to CSs. One way to do this is sug- gested by findings indicating that preexposure to a stimulus scheduled to be paired with shock can offset the ability of this event to serve as a CS (termed "latent inhibition"; Feldman, 1977; Lubow, 1973; Siegel \& Domjan, 1971). Given that the brief shocks used above may have mimicked some of the conditionable cues associated with ST, it follows that pre-ST exposure to these stimuli might negate their CS-like function. This would prevent these otherwise conditionable cues (but not necessarily ambient contextual cues) from entering into an associative linkage with fear during ST and thus, during testing, result in less fear being evoked in these same subjects in response to the punishment shocks.

Importantly, the logic guiding the present shock-CS account of attenuated ST punishment facilitation effects is the same for both pre- and post-ST exposures to brief shock. Both procedures should be effective in reducing the amount of fear that is associated with shock cues as a result of ST. However, whereas closely spaced CS presentations can be highly effective in offsetting conditioning in studies of latent inhibition (Crowell \& Anderson, 1972; Lubow, 1973) the present data suggested that, following ST, widely (Experiment 2) rather than closely (Experiment 1) spaced brief shocks may be more effective in offsetting the ST punishment intensification effect. A possible deduction from this is that rather than reducing the amount of fear conditioned to shock cues, a closely spaced post-ST shock regimen might even augment fear.

This shock-CS interpretation accordingly leads to the hypotheses that (1) closely spaced pre-ST exposures to brief shocks should offset ST punishment effects, whereas (2) the same regimen of post-ST exposures should either be uninfluential or perhaps even intensify the influence of ST. In Experiment 3, we tested these possibilities. In order to approximate the conditioning procedures typical of many CS preexposure studies, the ST treatment regimen in this study was shortened to a single session of ninety $10-\mathrm{sec}$ shocks. Elsewhere, this regimen has been highly effective (Crowell \& Anderson, 1981 ), and it entailed the same total amount of ST as was given in the present Experiments 1-2. Pilot data revealed that the closely spaced brief-shock exposures used in this study precluded the meaningful use of defecation as an index of conditioned, as opposed to unconditioned, emotionality. Nonetheless, evidence of (generalized) conditioned fear was obtained from recordings of response totals on the three lick-restabilization days prior to testing. Finally, four (rather than two) test trials were given, in order to better determine the time course of punishment learning.

\section{Method}

\section{Subjects}

Forty Sprague-Dawley rats, purchased from the same supplier as above, were used. All were reduced to $80 \%$ of their ad-lib body weight (maintained throughout the experiment) following the same water privation regimen used in the preceding studies. Pretreat- 
ment, treatment, pretest, and testing procedures were conducted at the same times of day as for these prior studies. The experiment again conformed with ARSC protocols.

\section{Apparatus \\ The treatment and test chambers and the shock circuitry and set- tings were also the same.

\begin{abstract}
Design
Five groups of 8 rats each were formed on the basis of the 3rd day of pretreatment water-lick training totals in the test chamber. Four of these were randomly assigned as part of a factorial experiment that involved exposure of two groups to a series of brief shocks (S) on each of 3 days prior to the ST day (i.e., the pre-ST exposure condition). One group from each pre-ST exposure condition was given ST on the next day. The controlling paradigm for this portion of the study thus conformed to a 2 (pre-ST brief shocks, no brief shocks) $\times 2(\mathrm{ST}$, no ST $) \times 4$ (test triais) MANOVA design. The fifth group was given the same ST, but the 3-day exposure routine to brief shocks was initiated on the day following this treatment.
\end{abstract}

\section{Procedure}

The experiment was conducted in two identical replications involving 4 subjects per group for each. All rats were given $10-\mathrm{min}$ lick-training sessions in the test chamber on each of 3 consecutive days. Lick totals for Day 3 were rank ordered, and a randomizedblocks design was employed to form and equate five groups of 8 subjects each on this measure. Beginning on the following day, each subject was introduced singly into the treatment chamber for equivalent periods on 4 consecutive days (i.e., Days 4-7). For Days 4-6, the rats of two groups daily were given ninety 0.25 -sec shocks on a variable-time (VT) schedule that averaged $80 \mathrm{sec}( \pm 40 \mathrm{sec})$ between each. The remaining rats were not shocked.

On Day 7 , the subjects of one $S$ and one non-S group were given ST consisting of 90 fixed-duration 10 -sec shocks distributed in accord with a VT70 $(70 \mathrm{sec}, \pm 30 \mathrm{sec})$ schedule (the rats of the other two groups spent identical time in the chamber but were not given ST; i.e., NST conditions). Thus, for four of the five groups, two were given 3 days of brief shocks and two were not, and one from each set then was given a session of ST (the other two were not), giving rise to Groups S-ST, S-NST, ST, and NST. The fifth group (Group ST-S) was given the same ST on Day 4, followed by 3 days of brief-shock exposures (identical regimen to the above).

Note that Group S-NST served as a comparison condition for the effects on testing of the brief-shock procedure per se. However, the time frame allocated for administration of these brief shocks (Days 4-6) for this group differed slightly from that for one of the two ST groups (Groups ST-S) that also were given these shortduration stimuli (Days 5-7). To evaluate the possible effects of this time difference, half of the subjects (within each replication) of Group S-NST were given short shocks on Days 4-6, and the other half (randomly determined), on Days 5-7. Since these subgroups performed identically on all dependent measures, they were combined and treated as a single condition.

Odors were again controlled by thoroughly cleaning and drying the ST chamber between respective subject placements for each day. The test chamber was also cleaned and dried between subject placements. Pretest lick response restabilization began on Day 8 and was carried out over 3 days (Days $8-10$ ) in the same way as in Experiments 1 and 2. However, unlike in the prior two experiments, response totals were recorded for each subject for each of these sessions. Response times to the first 100 and from the 101 st to the 110 th lick on the final pretest day (Day 10) were also measured. Finally, with the exception of giving four (rather than two) consecutive trials, testing was conducted on Day 11 , using the same procedure followed for Experiments 1 and 2.

\section{Results}

The replications variable did not contribute significantly to any of the outcomes of this study, so it will not be discussed further.

\section{Pretest Data}

Response totals. Lick-total averages were lower for the three ST conditions $(1308.9,1332.9$, and 1106.0 , for Groups ST, S-ST, and ST-S) than for either NST condition (1958.0 and 1901 .6 for Groups NST and S-NST) on the first (Day 8) but not the final two (Days 9-10) of the three pretest sessions. Moreover, although Group ST-S exhibited the lowest total of the three ST conditions, these groups did not differ statistically from each other for any of these sessions.

Statistical verification of these observations was obtained partly by subjecting the response-total data to a 2 $(\mathrm{ST}$, no ST) $\times 2$ (pre-ST brief shock, no brief shock) $\times$ 3 (pretest sessions) MANOVA, the major outcome being a significant ST $\times$ days interaction $[R(2,27)=8.16]$. Follow-up $2(\mathrm{ST}$, no ST) $\times 2$ (pre-ST brief shock, no brief shock) analyses applied to each day provided a significant effect of ST only on Day $1[F(1,28)=9.28]$. Finally, all comparisons involving Group ST-S paralleled those for Groups ST and S-ST.

Day 10 response times. Mean times for each group to make the first 100 licks on Day 10 (third pretest session) were relatively short and not different from one another. Averaged across groups, the mean time was $6.35 \mathrm{sec}$. Mean time to make the next 10 licks (i.e., licks 101-110) also did not differ between groups.

\section{Test Data}

Prepunishment lick times (baseline). Mean times for each group to make the first 100 licks on Day 11 are displayed as open (clear) columns in the left panel of Figure 4. As can be seen, all groups completed these licks quickly (overall mean $=6.29 \mathrm{sec}$ ) and at about the same rate. The $F$ values emerging from applications of either a 2 $(\mathrm{ST}$, no ST) $\times 2$ (pre-ST brief shock, no brief shock) factorial or simple one-way ANOVA involving all five groups did not support conclusions of statistical significance. These times were also not different from those taken to make the first 100 licks on the preceding day (Day 10; $F<$ 1.0 ). Nonetheless, to be consistent with previous analyses, these scores were used as covariates (where appropriate) in subsequent statistical applications.

Punishment effects. Although not quite as pronounced as for the first two studies, the punishment test contingency nonetheless again resulted in a marked increase in response times for all groups. This was revealed by comparing the latencies to the 10th response (following the first 100 licks) on the final pretest day (Day 10) with those collected in connection with the 10 responses following the initial test shock (Trial 1, Day 11). Averaged across groups, the time taken to complete Responses 101110 on Day 10 was $0.38 \mathrm{sec}$, whereas the averaged time 


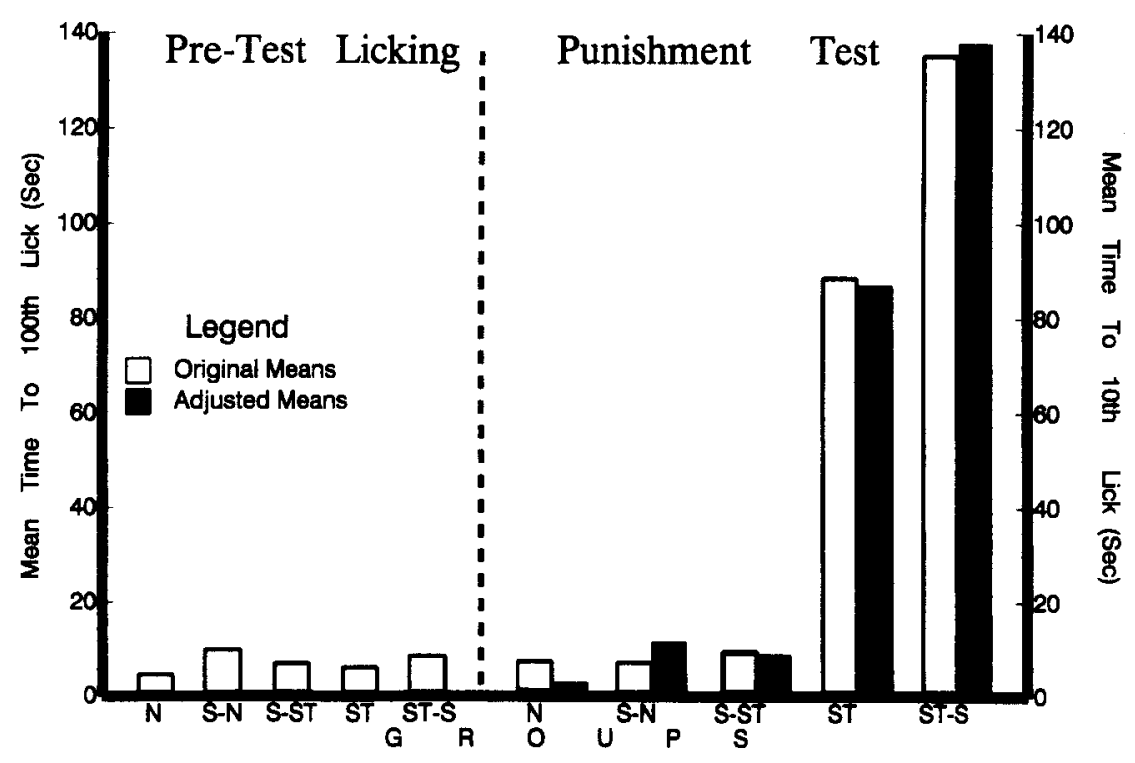

Figure 4. Mean lick times derived from prepunishment baseline (left panel) and punished test performances (right panel) for the groups of Experiment 3. The data were collected in the same manner and the legends are as those of Figure 3 . The order of the symbols $S$ and ST signifies whether or not the brief-shock regimen was given prior to or following the shock treatment.

(across groups) for the same number of responses following the initial test shock was $4.61 \mathrm{sec}[F(1,35)>30.0]$.

Mean times taken to complete 10 licks following each test shock, averaged for the four trials, are shown for each group as open (clear) columns in the right panel of Figure 4. The dark columns are for the same data after covariance adjustments due to baseline differences. Since both sets of data provide identical conclusions, discussion is based on the ANCOVA analysis. The right panel of Figure 4 reveals that two of the three ST groups (Groups ST and ST-S) showed the standard punishment intensification effect in that both exhibited much longer averaged times to complete 10 lick responses following each test shock than did any of the other subject sets. Moreover, of these two, Group ST-S showed an even longer averaged postpunishment time in meeting this response criterion than did Group ST. In contrast, the ST group given the brief shock regimen prior to ST (Group S-ST) and the two NST groups showed much shorter averaged times.

The only statistic emerging from the 2 (ST, no ST) $\times$ 2 (pre-ST brief shock, no brief shock) $\times 4$ (trials) MANCOVA applied to these data that failed to achieve significance was the $R$ value for the three-way ST $\times$ brief shock $X$ trials interaction $[F(3,84)=8.58, R(3,23)=2.8, p=$ $.065]$. Outcomes based on the effects for ST $[F(1,27)=$ $9.12]$, brief shock $[F(1,27)=11.22]$, trials $[R(3,23)=$ $4.11]$, and on the interactions between ST $\times$ brief shock $[R(1,27)=9.27]$, ST $\times$ trials $[R(3,23)=3.84]$, and brief shock $\times$ trials $[R(3,23)=3.99]$ were statistically reliable.

Follow-up 2 (ST, no ST) $\times 2$ (pre-ST brief shock, no brief shock) and simple groups (comparing S-ST, ST, and ST-S conditions) ANCOVAs for each test trial revealed that these interactions primarily resulted from a developing difference over trials between the relatively unchanging performances of Groups S-ST, S-NST, and NST and the marked increases in response latencies for Group ST that emerged on Trial 2 and became larger for each remaining trial. Trials-within-groups analyses supported these observations, revealing nonsignificant effects for Groups S-ST $[R(3,2)=2.04]$, S-NST $[R(3,2)=1.43]$, and NST $[R(3,2)=2.05]$, but significant effects for Groups ST $[R(3,2)=63.11]$ and $\mathrm{ST}-\mathrm{S}[R(3,2)=183.6]$.

Finally, a 3 (ST) $\times 4$ (trials) MANCOVA was applied to the test data collected for the three ST groups (i.e., Groups ST, S-ST, and ST-S). All three statistical outcomes achieved significance $\left[F_{\text {groups }}(2,20)=15.05\right.$, $R_{\text {trials }}(3,16)=26.9, R_{\text {groups }} \times$ trials $\left.(6,32)=6.19\right]$. Followup paired comparisons indicated significant differences between Group S-ST and ST on Trials 2-4, and between Group S-ST and ST-S on all four trials. The $F$ s based on the differences between Groups ST and ST-S also achieved significance on the final two test trials.

\section{Discussion}

The major finding of Experiment 3 was that subjects that were given brief shocks prior to ST did not show a punishment intensification effect during testing. This outcome, the same as that for the two NST control groups, is to be contrasted with the robust punishment intensification effects shown by ST subjects that either were not given brief shocks or were given these short stimuli following ST. The finding that the NST groups performed the same during the pretest and test sessions even though 
one received the brief-shock procedure is consistent with other outcomes (Miller, 1960) and with results from the first two studies. All of these suggest that a brief shock regimen alone, given away from the test environment, may not be a sufficient condition for the transfer of fear to that situation or for affecting punishment training therein (Karsh's, 1963, findings do not apply here, since her briefshock procedure was given in connection with responsecontingent food and in the same setting where testing occurred).

These data seem consistent with an emerging conclusion that the effectiveness of the present brief shock regimen depends exclusively on how and/or whether or not it is combined with ST. Although apparently ineffective if given alone, when given prior to ST, a closely spaced brief shock regimen fully nullified an otherwise robust ST effect. However, when given after ST, this same regimen intensified the intensifying effects of ST on punishment training. Importantly, these findings of either an enhancement of (Group ST-S), or a standard punishment intensification effect (Group ST), or of no effect at all on punishment training (Group S-ST) seem to negate interpretations that are based on differences in total amounts, numbers of shocks, and/or treatment-test intervals.

Instead, the present findings again implicate the role of conditioned fear as an account of ST punishment intensification effects. The present effects of antecedent, pre-ST exposures to brief shocks may arguably be understood as an instance of latent inhibition. If so, brief shocks repetitiously given before ST may have inhibited the cues of shock onset from developing a fear association with the painful by-products of prolonged exposure to the extended treatment shocks. Subsequent test shocks accordingly may have been less fear provoking for these than for ST subjects that were not given pretreatment brief shocks. In contrast, when given after ST, this same briefshock procedure may have functioned much like an extension of the treatment regimen. Since subjects were already conditioned to be fearful of shock cues during ST, consequent exposure to the closely spaced series of brief shocks (which, as noted, presumably exhibit US-like properties) thus may have served as a simple continuation of the original treatment. If so, Group ST-S arguably received the equivalent of 4 consecutive days of fear conditioning as opposed to a single day for Group ST.

Implications can also be derived from the present data regarding the respective roles of the two sources of fear (contextual; shock cues) postulated to result from ST. Although the presence of contextual fear in this study can be inferred from the attenuated response totals (indicating fear-promoted freezing; see Blanchard \& Blanchard, 1969; Bouton \& Bolles, 1980; Weiss, Kreikhaus, \& Conte, 1968) exhibited by ST groups on the first postST response restabilization day (Day 8), equivalent performances for all groups by the 3rd pretest day (Day 10) suggest that this source of fear was fully extinguished prior to testing. Moreover, in showing that all three ST groups exhibited equivalent suppression on the 1 st pretest day (indicating equal amounts of transferred fear), the fact that only two of these subsequently responded differently (from NST controls) to test shock seems further evidence that contextual fear did not contribute greatly to punishment intensification effects. In essence, these outcomes seem to suggest that the present punishment intensification effects were due mainly to the fear associated with shock cues.

The amount of suppression of punished licking for Groups ST and ST-S was, as has been noted, less in absolute terms than was observed for the ST-only groups of the first two experiments. Although both groups received the same overall amount of ST, the treatment regimen of the latter differed from that in Experiment 3 in terms of numbers of shock onsets and terminations, shock duration, and numbers of ST sessions. Although little systematic information exists on the effects of these variables, the collective findings from several studies permit tentative statements regarding their possible consequences. For example, Overmier and Seligman (1967, Experiment 2) reported rather large arithmetic differences in ST effects on shuttlebox learning traceable to variations in the number and duration of the shocks of ST given in a single session to dogs. Further, Crowell and Anderson (1981) reported significantly greater impairment of shuttle performance in rats for 10 - versus 5 -sec treatment shock durations. Although confounded by number (but see Crowell \& Anderson, 1981), the findings of both reports suggest that longer shocks may result in more pronounced effects on test performance than those of shorter ones. Thus, that Experiments 1 and 2 employed very long 180-sec shocks (on consecutive days) may explain the more pronounced effect of ST on these test performances than was observed in connection with the 10 -sec durations involved for Experiment 3.

Indeed, while comparisons may again be problematic because of different amounts and numbers of onsets and terminations, the general finding that groups receiving only a brief shock regimen (i.e., Groups NST-S in all three experiments) did not show an ST punishment intensification effect also is consistent with the possibility that longer treatment shocks exert more potent effects. Considered together, these outcomes suggest that ST effects are dependent on the use of treatment shock durations that are considerably longer than those employed in standard fear conditioning studies.

\section{GENERAL DISCUSSION}

The present research was guided by the presumption that fear responses acquired during ST generalize to the test environment and influence performances therein. In so transferring, the freezing that normally accompanies fear is believed to be incompatible with tests requiring action and compatible with those demanding response suppression. Thus, for studies involving a punishment test, subjects that transfer fear acquired during ST would accordingly be expected to exhibit more rapid and complete response suppression learning than those that do not. In the present tests of this theory, when procedures were 
used that nullified all sources of fear otherwise attributable to ST, subjects exhibited punishment training functions that were comparable to those for no-ST controls. In contrast, marked acceleration of punishment learning occurred for ST subjects that were not exposed to these fear-nullification procedures. In repeatedly showing that these fear-nullification procedures alone did not influence test performance, it was also possible to rule out both these and the ST regimen as sufficient conditions for the intensification of punishment learning.

Apart from the direction of effects because of use of a test task requiring response activation, the present analysis is analogous to the theoretical accounts of ST interference effects proposed by Minor et al. (1991) and Anderson et al. (1995). Indeed, in providing evidence that the cues of ST may serve as CSs for fear that mediate the occurrence of the punishment intensification effect, the present outcomes are consistent with the earlier contentions of Brookshire et al. (1961) and Anderson et al. (1968) of common mechanisms in accounting for the broad range of ST effects.

Interestingly, exposure in the present experiments to a series of brief shocks as a means of nullifying the effects of the much longer shocks of ST may seem comparable to procedures that define US-reinstatement phenomena. These phenomena concern modification of the ability of a US to affect conditioning simply by following (or preceding) it with exposures to a similar event that otherwise differs in intensity, duration, or some other influential parameter (e.g., Bouton, 1984; Randich, 1981; Randich \& LoLordo, 1979; Rescorla, 1973, 1974; Rescorla \& Cunningham, 1977; Rescorla \& Heth, 1975). Current speculation regarding US-reinstatement effects is that the "mental image" and corresponding impact of a US can be altered by consequent (or antecedent) exposures to USlike events that are functionally different in some way from the US per se. This notion also assumes symmetrical effects, in that the relative intensity of such events can either devalue (if less intense than the US) or inflate (if more intense) a US "image."

In applying this theory to Experiments 1 and 2, one might reason that the brief shock procedure devalued the "image" for the ST shocks, as opposed to extinguishing fear of shock cues. A result of this might have been to alter the subject's expectation for subsequent shock to be more in accord with that of non-ST animals, thus explaining the lack of an ST effect for these rats. However, this notion seems unable to reconcile the different effects associated with spacing the otherwise identical briefshock regimens of these two experiments.

A US-reinstatement interpretation of Experiment 3 also encounters difficulties. An antecedent (to ST) briefshock procedure should have established a relatively weak "image" of the US. The subsequent, much longer shocks of the ST thus effectively should have "upgraded," intensified, or inflated the "image" of this event (which, in turn, should have functioned to strengthen-or at least not weaken - the connection with whatever stimuli might have been contingent with its original presentation). In "inflating" a US "image" in this manner, such should not have degraded the proactive impact of ST as a source of intensified punishment learning in the subsequent test. However, instead of differentially responding to test shock as might be assumed by this theory for the antecedent brief-shock procedure, the S-ST subjects responded as if it were no different than for the NST or S-NST subjects. Instead, it was as if the antecedent brief-shock regimen "erased" rather than intensified the memory of the ST experience (Rescorla \& Cunningham, 1977). The equivalent performances of the S-ST, NST-S, and NST groups in Experiment 3 thus seem to discomfirm a USreinstatement interpretation of the effects of the briefshock procedures that were used.

Another seeming prediction from US-reinstatement theory is that arranging (about) the same number of equivalently spaced brief shocks to follow the much longer shocks of ST in Experiment 3 should have devalued the "image" of the latter. In attenuating the "image" of the ST shocks in this manner, this should have offset any tendency by the ST-S subjects to show intensified punishment learning. However, in showing intensification of intensified punishment learning, the subjects of Group ST-S behaved as if an already potent "image" for the much longer shocks of the ST had been augmented by the postST, brief-shock procedure.

A final concern for US-reinstatement theory emerges from the evidence for contextual fear provided in Experiment 3. Alterations in the "image" of the US by the various brief-shock procedures that were used putatively should have been reflected in different amounts of fear being conditioned to the ambient contextual cues of the treatment chamber and then generalized to the test situation. Subjects with a devalued "image" of the US should have transferred less fear, and subjects with an inflated "image" should have transferred more, than those whose "image" was unaltered (i.e., all ST-only groups). That the ST groups of Experiment 3 showed equivalent amounts of pretest response suppression, regardless of whether or not they had been given a brief shock regimen, thus again seems inconsistent with expectations based on USreinstatement theory.

A possible reason for these seeming shortcomings of US-reinstatement theory is that it may not apply to USlike events that are as intense, prolonged, and/or as numerously given as is typically the case for standard ST procedures. Indeed, most tests of US-reinstatement theory have involved conditioned suppression or autoshaping paradigms that normally entail a few pairings of a discrete CS with a short-duration US. These procedural differences make comparisons with the present research highly problematic.

It is useful to evaluate how other theoretical accounts of ST effects might reconcile the present data-namely, those involving cognitive, physiochemical, or innate mechanisms. Consider, first, learned-helplessness (LH) theory. None of the outcomes of the present experiments appear to be compatible with the two major suppositions of this theory - that inescapable shocks promote the de- 
velopment of an independence cognition and/or a reduction in response incentive. For example, the commonplace ST punishment intensification effect is itself contrary to expectations generated by $\mathrm{LH}$. This is because the manifestation of interference engendered by an independence cognition is theorized to retard rather than to facilitate the acquisition of test behaviors that are motivated by shock. In addition, since all of the pretest shocks used in these experiments were fixed in duration, they were by definition (see Maier et al., 1969) inescapable and uncontrollable. But, depending on how and when the inescapable shocks of the brief-shock regimen were introduced, these events, as has been noted, either negated or intensified the effects of ST and, when given alone, exerted no effect at all.

Nonetheless, the apparent deduction from LH theory regarding the effect of these brief-shock procedures would be the development and/or cumulative strengthening of the independence cognition in every instance involving their use. In transferring these cognitive outcomes to the test situation, the prediction by LH theory would seemingly be increasingly marked retardation of punishment learning respectively for Groups NST-S, ST-only, ST-S, and S-ST (this prediction is the same for the $\mathrm{LH}$ assumption of attenuated motivation as well). In direct contrast to these predictions, the present outcomes led to the paradoxical conclusion that an otherwise relatively inconsequential procedure involving abbreviated inescapable shocks can either offset or intensify punishment learning when combined in various ways with another inescapable shock procedure that, alone, markedly intensifies response suppression learning.

A final point regarding $\mathrm{LH}$ theory concerns the many studies designed to "immunize" subjects against the development and/or presence in the test situation of an independence cognition (see Warren, Rosellini, Plonsky, $\&$ DeCola, 1985). The prototype for "immunization" is the research of Seligman and Maier (1967), who trained some of their subjects (dogs) to perform the test response prior to ST. This putatively established an association of "control" that was reasoned to remain preeminent throughout ST and thus prevent the development of the so-called independence cognition that otherwise putatively resulted from exposure to inescapable ST.

Because of the apparent similarity between these preST "immunizing" techniques and the brief-shock procedure given Group S-ST in Experiment 3, the possibility arises that this group may have been cognitively immunized rather than subject to the latent inhibition of fear. Several considerations weigh against this possibility. First, since the brief shocks of the present experiments were programmed to occur independently of any response that subjects might make at time of delivery, this regimen probably cannot be considered "control" training. Second, these brief shocks were given in the treatment and not the test setting, which seems to be a significant departure from standard immunization methods.

Recent physiochemical accounts of ST effects have mostly been guided by evidence showing that stress can promote the release of endogenous chemicals that serve a pain-reducing (analgesic) function (Grau, 1987; Maier \& Keith, 1987). This evidence has suggested to some that certain of the so-called interference effects attributable to ST may be mediated by this physiochemical mechanism (Maier, Sherman, Lewis, Terman, \& Liebeskind, 1983). For example, the evidence that ST may facilitate the release of these chemicals upon subsequent encounters with shock provides a basis for the possibility of an elevated pain threshold and a consequent reduction in the functional intensity of test shock for these subjects. This, in turn, could explain the many reports of impaired shock-motivated performances such as shuttlebox escape/avoidance learning following ST.

However, a functional elevation in pain threshold (see Anderson et al., 1968, Experiment 5; Littman, Stevens, \& Whittier, 1964) cannot explain the highly reliable ST punishment intensification effect illustrated in the present experiments. If anything, an elevated pain threshold due to prior ST should result in less rather than enhanced responsiveness to test shock, which in turn would lead to a prediction of attenuated punishment learning. The present reliable outcome of intensified punishment learning thus represents a disconfirmation of a physiochemical interpretation of the ST effects reported here.

Moreover, it is not clear how a physiochemical theory could account for the effects reported for the brief-shock procedures used in this research. The pre-ST exposure procedure likely provoked the emission of enkelphins and the possible conditioning of this response to the cues of the treatment setting. The return of these subjects to this environment for administration of ST thus arguably may have resulted in the pretreatment release of painreducing endorphins and an attendant elevation in pain threshold (i.e., an attenuated sensation of pain). A possible consequence of this would be a reduction in the functional intensity of the shocks of the ST. Given that shock intensity influences the strength of acquired fear (Annau \& Kamin, 1961), this analysis leads to the possibility that the contextual cues of the treatment chamber (and, possibly, the cues of shock onset) were paired with functionally weaker shocks for the S-ST group than for the other ST groups.

One consequence of this is that Group S-ST should have, for example, transferred less contextually based fear to the test setting than should either the ST-only or the ST-S subjects in Experiment 3. However, the equivalent reductions in lick response totals on the initial pretest day on this study (Day 8) suggest that all three ST groups transferred similar amounts of contextually mediated fear, thus posing a problem for this interpretation.

Finally, for this conditioned-endorphin account to have merit, it must be reconciled with the evidence from Experiment 3 that it did not apply equally to Group ST-S in similarly elevating the pain threshold of these subjects during their receipt of the brief shock regimen. Given that the preceding ST also should have promoted a conditioned endorphin response to contextual cues, this should have served to functionally reduce (through an el- 
evated shock threshold) the impact of these abbreviated stimuli for this group. That this apparently did not occur can be seen from the added intensification of punishment training wrought by the ST-S procedure.

The present data may reflect on a recent proposal by Minor et al. (1991) that ST intensifies neophobic responses-namely, that ST may increase the nonassociatively based (innate?) fear of rats to novel stimuli such as perhaps occurs upon initial exposure to a new test situation. Though difficult to operationalize, a neophobic reaction might be identified by the presence of freezing in a setting where the possibility of any associatively established fear has been eliminated. Several lines of evidence argue against this interpretation of the present effects. For example, extinction of associatively based fear by repeated exposures of ST rats to the contextual stimuli of the treatment environment eliminated any differences in freezing from NST subjects upon their introduction into the test setting (Experiments 1 and 2). Moreover, procedures designed to extinguish (or to prevent the development of) fear to shock cues further eliminated differential responses to test shock between ST and NST groups as well. Taken together, the data of all three experiments seemed to show that when all sources of associatively based fear were eliminated, so too was evidence of ST effects.

\section{REFERENCES}

ANDERSON, D. C. (1966). Prior shock trauma and test-shock intensity as determinants of escape learning. Psychological Reports, 19, 771-778.

ANDERson, D. C. (1993). Does ACTH mediate the punishmentintensification effect of prolonged, fixed-duration treatment shocks? Psychobiology, 21, 43-49.

Anderson, D. C., Cole, J., \& McVaugh, W. (1968). Variations in unsignaled inescapable preshock as determinants of responses to punishment. Journal of Comparative \& Physiological Psychology Monograph Supplement, 65 (3, Pt. 2), 1-17.

anderson, D. C., Crowell, C. R., Boyd, N. R., \& Hantula, D. A. (1995). Fixed-duration shock treatment: Pre- and posttreatment stimulation, activity, and skin resistance as predictors of escape performance. Psychobiology, 23, 329-344.

anderson, D. C., Crowell, C. R., Cunningham, C. L., \& Lupo, J. V. (1979). Behavior during shock exposure as a determinant of subsequent interference with shuttle box escape-avoidance learning in the rat. Journal of Experimental Psychology: Animal Behavior Processes, 5, 243-257.

Anderson, D. C., Crowell, C. R., Koehn, D., \& Lupo, J. V. (1976) Different intensities of unsignalled inescapable shock treatments as determinants of non-shock-motivated open field behavior: A resolution of disparate results. Physiology \& Behavior, 17, 391-394.

anderson, D. C., Plant, C., \& Paden, P. (1967). Conditioned suppression of a running response as related to competing responses, drive, and basal skin resistance. Journal of Comparative \& Physiological Psychology, 63, 282-287.

anisman, H., DeCatanzaro, D., \& Remington, G. (1978). Escape performance following exposure to inescapable shock: Deficits in motor response maintenance. Journal of Experimental Psychology: Animal Behavior Processes, 4, 197-218.

Anisman, H., \& SkLaR, L. S. (1979). Catecholamine depletion in mice upon preexposure to stress: Mediation of the escape deficits produced by inescapable shock. Journal of Comparative \& Physiological Psychology, 93, 610-625.

AnNaU, Z., \& Kamin, L. J. (1961). The conditioned emotional response as a function of intensity of the US. Journal of Comparative \& Physiological Psychology, 54, 428-432.
Balliene, B., \& JoB, R. F. S. (1991). Reconsideration of the role of competing responses in demonstrations of the interference effect (learned helplessness). Journal of Experimental Psychology: Animal Behavior Processes, 17, 270-280.

Bersh, P. J., Whitehouse, W. G., Laurence, M. T., Blustein, J. E., \& ALLOY, L. B. (1990). Signaling the duration of uncontrollable shock impairs subsequent shock escape. Psychological Record, 40, 113-125.

Black, A. H. (1977). Comments on "Learned-Helplessness: Theory and Evidence" by Maier and Seligman. Journal of Experimental Psychology: General, 106, 41-43.

Blanchard, R. J., \& Blanchard, C. D. (1969). Crouching as an index of fear. Journal of Comparative \& Physiological Psychology, 67, 370-375.

Bouton, M. E. (1984). Differential control by context in the inflation and reinstatement paradigms. Journal of Experimental Psychology: Animal Behavior Processes, 10, 56-74.

Bouton, M. E., \& Bolles, R. C. (1980). Conditioned fear assessed by freezing and by the suppression of three different baselines. Animal Learning \& Behavior, 8, 429-434.

Brookshire, K. H., Littman, R. A., \& Stewart, C. N. (1961). Residua of shock-trauma in the white rat: A three-factor theory. Psychological Monographs: General \& Applied, 75 (10, Whole No. 514), 1-32.

Campbell, B. A., \& Teghtsoonian, R. (1958). Electrical and behavioral effects of different types of shock stimuli on the rat. Journal of Comparative \& Physiological Psychology, 51, 185-192.

Crowell, C. R. (1974). Conditioned-aversive aspects of electric shock. Learning \& Motivation, 5, 209-220.

Croweli, C. R., \& ANDERSon, D. C. (1972). Variations in intensity, interstimulus interval, and interval between preconditioning CS exposures and conditioning with rats. Journal of Comparative \& Physiological Psychology, 79, 291-298.

Crowell, C. R., \& Anderson, D. C. (1979). Shuttle interference effects in the rat depend upon activity during prior shock: A replication. Bulletin of the Psychonomic Society, 14, 413-416.

Crowell, C. R., \& ANDERSon, D. C. (1981). Influence of duration and number of inescapable shocks on intrashock activity and subsequent interference effects. Animal Learning \& Behavior, 9, 28-37.

Cunningham, C. [L.], \& Anderson, D. C. (1974). The effects of a 39 $\mathrm{kHz}$ tone on passive-avoidance learning in preshocked rats: A failure to replicate. Bulletin of the Psychonomic Society, 3, 121-122.

Feldman, M. A. (1977). The effects of preexposure to a warning or a safety signal on the acquisition of a two-way avoidance response in rats. Animal Learning \& Behavior, 5, 21-24.

GLAZER, H. I., \& WEISS, J. M. (1976). Long-term interference effect: An alternative to "learned helplessness." Journal of Experimental Psychology: Animal Behavior Processes, 2, 202-313.

GraU, J. W. (1987). Activation of the opioid and nonopioid analgesic systems: Evidence for a memory hypothesis and against the coulometric hypothesis. Journal of Experimental Psychology: Animal Behavior Processes, 13, 215-225.

HolLis, K. L., \& Overmier, J. B. (1973). Effective inescapable shock on efficacy of punishment of appetitive responding by dogs. Psychological Reports, 33, 903-906.

KARSH, E. B. (1963). Changes in intensity of punishment: Effect on running behavior of rats. Science, 140, 1084-1085.

KurTZ, J. H., \& PEARL, J. (1960). The effects of prior fear experience on acquired-drive learning. Journal of Comparative \& Physiological Psychology, 53, 201-206.

KurTZ, J, H., \& Walters, G. C. (1962). The effects of prior fear experiences on an approach-avoidance conflict. Journal of Comparative \& Physiological Psychology, 55, 1075-1078.

LeVine, S., Madden, J., IV, Conner, R. L., Moskal, J. R., \& Anderson, D. C. (1973). Physiological and behavioral effects of prior aversive stimulation (preshock) in the rat. Physiology \& Behavior, 10, 467-471.

LEVIS, D. (1976). Learned helplessness: A reply and alternative S-R interpretation. Journal of Experimental Psychology: General, 105, 47-65.

Littman, R. A., Stevens, R. A., \& Whitman, J. L. (1964). Previous shock experiences and response threshold to shock. Canadian Journal of Psychology, 18, 93-100.

Lubow, R. E. (1973). Latent inhibition. Psychological Bulletin, 79, 398-407. 
MAIER, S. F. (1990). Role of fear in mediating shuttle escape learning deficit produced by inescapable shock. Journal of Experimental Psychology: Animal Behavior Processes, 16, 137-149.

Maier, S. F., Albin, R. W., \& TESTA, T. J. (1973). Failure to learn to escape in rats previously exposed to inescapable shock depends on the nature of the escape response. Journal of Comparative \& Physiological Psychology, 85, 581-592.

Maier, S. F., Davies, S., Grau, J. W., Jackson, R. L., Morrison, D. H., MoYe, T., Madden, J., IV, \& Barchas, J. D. (1980). Opiate antagonists and long-term analgesic reaction induced by inescapable shock in rats. Journal of Comparative \& Physiological Psychology, 94 1172-1183.

MAIER, S. F., \& KEITH, J. R. (1987). Shock signals and the development of stress-induced analgesia. Journal of Experimental Psychology: Animal Behavior Processes, 13, 226-238.

Maier, S. F., \& Seligman, M. E. P. (1976). Learned helplessness: Theory and evidence. Journal of Experimental Psychology: General, $105,3-46$.

Maier, S. F., Seligman, M. E. P., \& Solomon, R. L. (1969). Pavlovian conditioning and learned helplessness: Effects on escape and avoidance behavior of (a) CS-US contingency and (b) the independence of the US and voluntary responding. In B. A. Campbell \& R. M Church (Eds.), Punishment and aversive behavior (pp. 299-342). New York: Appleton-Century-Crofts.

Maier, S. F., Sherman, J. E., Lewis, J. W., Terman, G. W., \& LiebesKIND, J. C. (1983). The opioid/nonopioid nature of stress-induced analgesia and learned helplessness. Journal of Experimental Psychology: Animal Behavior Processes, 9, 80-90.

MiLlER, N. E. (1960). Learning resistance to pain and fear: Effects of overlearning, exposure, and rewarded exposure in context. Journal of Experimental Psychology, 60, 137-145.

MineKa, S., COOK, M., \& Miller, S. (1984). Fear conditioned with escapable and inescapable shock: Effects of a feedback stimulus. Journal of Experimental Psychology: Animal Behavior Processes, 10, 307-323.

MinOR, T. R. (1990). Conditioned fear and neophobia following inescapable shock. Animal Learning \& Behavior, 18, 212-226.

MiNOR; T. R., DESS, N. K., \& OVERMIER, J. B. (1991). Inverting the traditional view of "learned helplessness." In M. R. Denny (Ed.), Fear, avoidance, and phobias: A fundamental analysis. Hillsdale, NJ: Erlbaum.

MinOR, T. R., \& LoLoRDo, V. M. (1984). Escape deficits following inescapable shock: The role of contextual odor. Journal of Experimental Psychology: Animal Behavior Processes, 10, 168-181.

O'Brien, R. G., \& KAISER, M. K. (1985). MANOVA method for analyzing repeated measures designs: An extensive primer. Psychological Bulletin, 97, 316-333.

Overmier, J. B. (1988). Psychological determinants of when stressors stress. In D. Hellhammer, I. Florin, \& H. Weiner (Eds.), Neurobiological approaches to human disease (pp. 236-259). Toronto: Hans Huber.
Overmier, J. B., \& Seligman, M. E. P. (1967). Effects of inescapable shock on subsequent escape and avoidance learning. Journal of Comparative \& Physiological Psychology, 63, 28-33.

Pearl, J., Walters, G. C., \& Anderson, D. C. (1964). Suppressing effects of aversive stimulation on subsequently punished behavior. Canadian Journal of Psychology, 18, 343-355.

RANDICH, A. (1981). The US preexposure phenomenon in the conditioned suppression paradigm: A role for conditioned situational stimuli. Learning \& Motivation, 12, 321-341.

RANDICH, A., \& LoLoRDO, V. M. (1979). Associative and non-associative theories of the UCS preexposure phenomenon: Implications for Pavlovian conditioning. Psychological Bulletin, 86, 523-548.

ResCoRla, R. A. (1967). Pavlovian conditioning and its proper control procedures. Psychological Review, 74, 71-80.

RESCORLA, R. A. (1973). Effect of US habituation following conditioning. Journal of Comparative \& Physiological Psychology, 82, 137-143.

RESCORLA, R. A. (1974). Effect of inflation on the unconditioned stimulus value following conditioning. Journal of Comparative \& Physiological Psychology, 86, 101-106.

Rescorla, R. A., \& CunNingham, C. L. (1977). The erasure of reinstated fear. Animal Learning \& Behavior, 5, 386-394.

ResCoRla, R. A., \& HETH, D. C. (1975). Reinstatement of fear to an extinguished conditioned stimulus. Journal of Experimental Psychology: Animal Behavior Processes, 1, 88-96.

Seligman, M. E. P., \& Maier, S. F. (1967). Failure to escape traumatic shock. Journal of Experimental Psychology, 74, 1-9.

Siegel, S., \& Domjan, M. (1971). Backward conditioning as an inhibitory procedure. Learning \& Motivation, 2, 1-11.

WALTERS, G. C., \& Rogers, J. V. (1963). Aversive stimulation of the rat: Long-term effects on subsequent behavior. Science, 142, 70-71.

Warren, D. A., Rosellini, R. A., Plonsky, M., \& DeCola, J. P. (1985). Learned helplessness and immunization: Sensitivity to response-reinforcer independence in immunized rats. Journal of Experimental Psychology: Animal Behavior Processes, 11, 576-590.

Weiss, J. M., Glazer, H. I., \& Pohorecky, L. A. (1976). Coping behavior and neurochemical changes: An alternative explanation for the original "learned helplessness" experiments. In G. Serban \& A. Kling (Eds.), Animal models in human psychobiology. New York: Plenum.

Weiss, J. M., Goodman, P. A., Losity, B. G., Corrigan, S., Charry, J. M., \& BAILEY, W. H. (1981). Behavioral depression produced by an uncontrollable stressor: Relationship of norepinephrine, dopamine, and serotonin levels. Brain Research Reviews, 3, 167-205.

Weiss, J. M., Kreikhaus, E. E., \& Conte, R. (1968). Effects of fear conditioning on subsequent avoidance behavior and movement. Journal of Comparative \& Physiological Psychology, 65, 413-421.

(Manuscript received April 13, 1995; revision accepted for publication April 11, 1996.) 